\title{
Competences of Social Interaction and their Role in the Process of Physical Education
}

\author{
Bolotnikov A.A. \\ University of Management "TISBI" \\ Kazan, Russia \\ tank.rt@mail.ru
}

\author{
Imangulov R.Sh. \\ Kazan State University of Architecture and Civil \\ Engineering \\ Kazan, Russia \\ imangulovr@inbox.ru
}

\author{
Gimadeev R.N. \\ Physical Education Departament \\ University of Management "TISBI" \\ Kazan, Russia \\ tank.rt@mail.ru
}

\begin{abstract}
Defining the conditions of social interaction in the educational process, we note many factors that determine the point of its participants' contact. Effective communication is designed to reduce the level of tension and detachment of students, which in turn gives grounds and opportunities to intensify the activities of the training.

In modern conditions, physical training is an important element in the education system at all levels. It determines the need for the formation of competencies focused on social interaction. Social communication should be naturally integrated into the pedagogical process and oriented to a clear understanding of the values and targets in the process of physical training.
\end{abstract}

Keywords—physical training; social communication; factors of interaction; social reference points; values.

\section{INTRODUCTION}

Determining the relevance of the social interaction problem study, it should be noted that increasing interest in physical fitness is a trend in recent years, which determines multilateral interest in this issue. According to All-Russian Public Opinion Research Center, the proportion of Russian residents involved in sports with this or that frequency increased from $38 \%$ in 2006 to $60 \%$ in 2018: including $17 \%$ of respondents who train daily, $22 \%$ - several times a week, $10 \%$ - once a week, 5\% - several times a month, 6\% several times a year. [1]

The digitalization of sports has also significantly affected the perception of sports in the social reality of our time. The main dissemination of information on sports clubs, leagues and events now takes place on the Internet, new broadcasting opportunities are being developed, a key tool for the sport club to interact with fans is a smartphone, which now anyone can "get" without enormous expenses compared to those that television and outdoor advertising usually have to bear.
The main tasks of physical training are:

- recreational and progressing (to promote health and increase in working efficiency);

- instructional (for learning the necessary amount of knowledge in the field of physical training in order to acquire special motor skills and mastering the scientific and practical fundamentals of physical training);

- educational (for the formation of a motivationalvalue attitude to physical culture and physical selfimprovement).

\section{LITERATURE REVIEW}

Sobon identifies three main forms of organization of training courses in sports:

- $\quad$ training sessions in sports groups and teams;

- sports competitions and independent training groups;

- training sessions in sport groups and teams conducted according to the approved schedule [2].

Most scientists and tutors recognize the importance of physical fitness in the formation of a socially active person. The formation and development of physical training is a common goal of physical education. Today, in the context of the scientific and technological progress active development, there is an increasing need for activities involving the conditions of excessive energy consumption (physical, intellectual, mental). This is noted by many scientists, such as M. Ya. Vilensky and L.P. Matveev [3,4].

Physical training is a new systemic, dynamic formation of the personality. It gives the opportunity to combine motivationally significant, action-practical, cognitive, 
reflective-regulatory traits of the personality and enhance their effect.

The value of physical training resides with the fact that sport helps the development of mental activity, contributes to a high level of sensory, intellectual, emotional and volitional processes development; physical training contributes to the preservation of health for a long time.

Physical training and sports is a key activity, since it is aimed at a person progressing from physical and mental point of view.

L.I. Lubysheva admits that the physical education of the individual certainly includes physical training and sports activities. And this is considered a prerequisite for an individual the physical culture formation. Based on the results of the research, L.I. Lubysheva proves that students who are systematically involved in sports, have an increased vitality, self-confidence and optimism. A low assessment of sports activities spiritual value may be the result of a low educational level. [5]

The level of self-regulation is formed under the influence of physical culture and sports activities, making students more confident, increasing their working capacity and strengthening their stress resistance.

I.A. Zimnyaya divides competences into three groups:

- $\quad$ a key competence (ensuring normal functioning in modern society) [6];

- a professional competence (providing the ability to actively solve emerging problems at the workplace, using a creative approach and existing experience in the professional field);

- a social competence (providing the ability of the graduate to interact with society, other people).

\section{RESEARCH METHODOLOGY}

When determining the forms and methods used in the educational process, it is important to note the importance of competitive activity. Competition is a way to develop motor skills and increase fitness. Competitions contribute to the formation of strong-willed traits of character and a positive emotional background [7,13]. The success of any type of competition depends on the thoroughness of preparation for it and the level of reasoning [8]. The proper organization of competitions contributes to the improvement of sports results and, in this way, is an effective tool for the popularization of sports [9].

Athletic training is a generalized category of activity in the form of competition and getting ready for it to achieve ultimate results in the chosen fields of sports. For this, the participants in the competition need to maximize their psychophysical abilities, mobilize their reserve capabilities in time. VC. Balsevich states that the process of sports training should be based on the goals and objectives of students, their interests and inclinations [10].

Considering modern conditions of communication in the academic process, it should be noted that in the process of implementing physical fitness in modern conditions, such forms as a lecture - visualizations, game simulations and case-study methods are used. A game imitation is a method of developing cooperation and offers solutions to tasks that are performed by small groups with the distribution of roles. The case method is an analysis of specific situations that may arise during the competition.

Besides, during training, students learn all necessary legal documentation that ensures the organization and conduct of sporting events at various levels. A special place in the educational process is occupied by the study of the Federal Law "On Physical Culture and Sport in the Russian Federation" No. 329 FZ dated December 4, 2007, with annual amendments. It is the legislative basis for the organization and conduct of competitions. [11]

Let us consider the main directions of social interaction in the process of physical training. Competitive activity is an integral part of a physical training process and has a tremendous motivating potential. It is worth noting that competition is a specific physical training, and, unlike general, it makes it possible to increase the existing level of functionality and provide the necessary energy base for the improvement of technical and tactical skills [12].

Competitions help to solve pedagogical, athletic, methodological and socio-political problems. At sports competitions physical, technical, tactical, mental and theoretical qualification is being improved. These indicators are also characteristic of ordinary classes; however, they act with greater force in competitions, therefore a competition is the most effective measure to increase the athletes' fitness. Especially important are competitions for the formation of strong-willed traits of character. Competitions contribute to the development of physical training and sports in general and have a pedagogical effect on the attending spectators.

\section{IV.RESULTS}

Having examined general theoretical approaches to the significance of the social function in education, in particular in sports training, it is important to note that the implementation of social competence in the process of physical training is focused on effective interaction with students. In this context, the development of forms for conducting periodic surveys is proposed. Questions that could give you an opportunity to identify the values and orientation of students social interaction, as well as their attitude to physical fitness, should be put forward. Surveys in the structure of the educational process will form criteria and factors that determine the effectiveness of this kind of social interaction. Of particular value are the dynamic and time-expanded changes in the subjective perception of the physical fitness. 


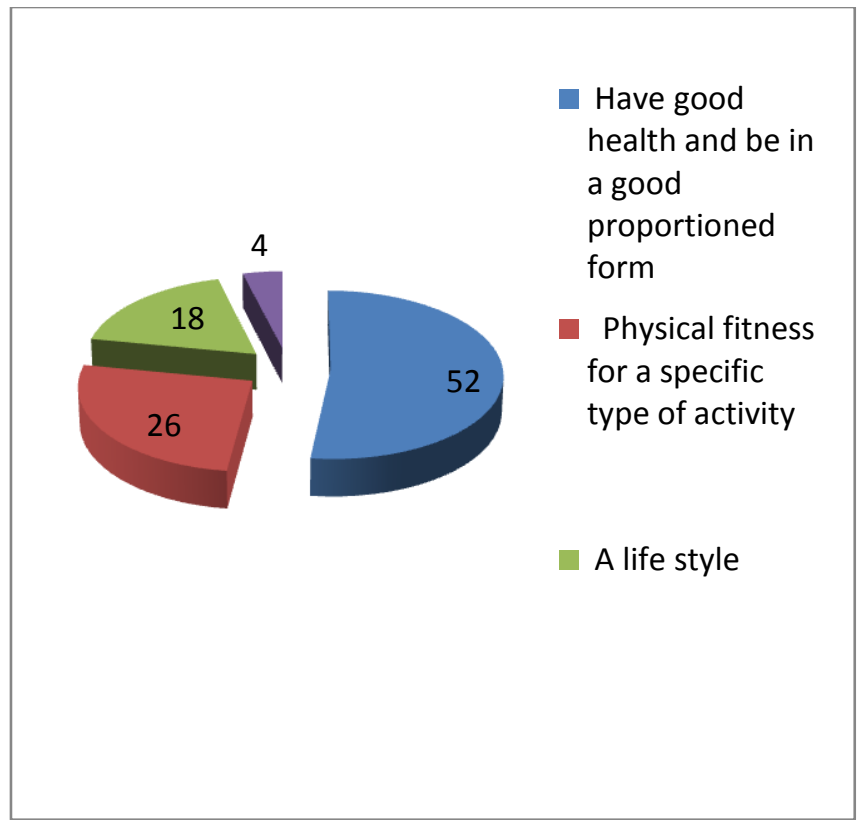

Fig. 1. The reasons to do sports and take physical training courses

We tried to define principles and main directions of physical training using a form of social interaction - a survey. Through the survey, one can determine the orientation and target orientations of students in the process of physical training.

As part of the study, a special survey that revealed the main accents in the perception of physical fitness has been carried out. Most students recognize the importance of physical education and sports for health. This concept will allow to build a physical training course taking into account the characteristics of the health of students, develop programs taking into account specifics and needs.

We defined principles and main directions of physical training using a form of social interaction - a survey. Through the survey, one can determine the tendency and target orientations of students in the process of physical training.

As part of the given study, a survey that revealed the main accents in the perception of physical fitness was conducted. Most students recognize the importance of physical education and sports for health. This concept will give the possibility to build such physical training course that will take into account the characteristics of students health, develop programs taking into account their preferences and specific needs.

- Of course, regularly visit sport groups, clubs

- Only sometimes

- I spare minimum of my time to physical training

- Fill-in-the- blank yourself

Most of the respondents do not do sports regularly. The majority of young people perceive physical culture not very positively. They do not always see the inter relationship between physical culture and general culture. It is important to pay attention to the answers that are formed in free form: almost $90 \%$ of the answers are related to the need to maintain physical fitness (athletic physique, weight loss, slimness, etc.)
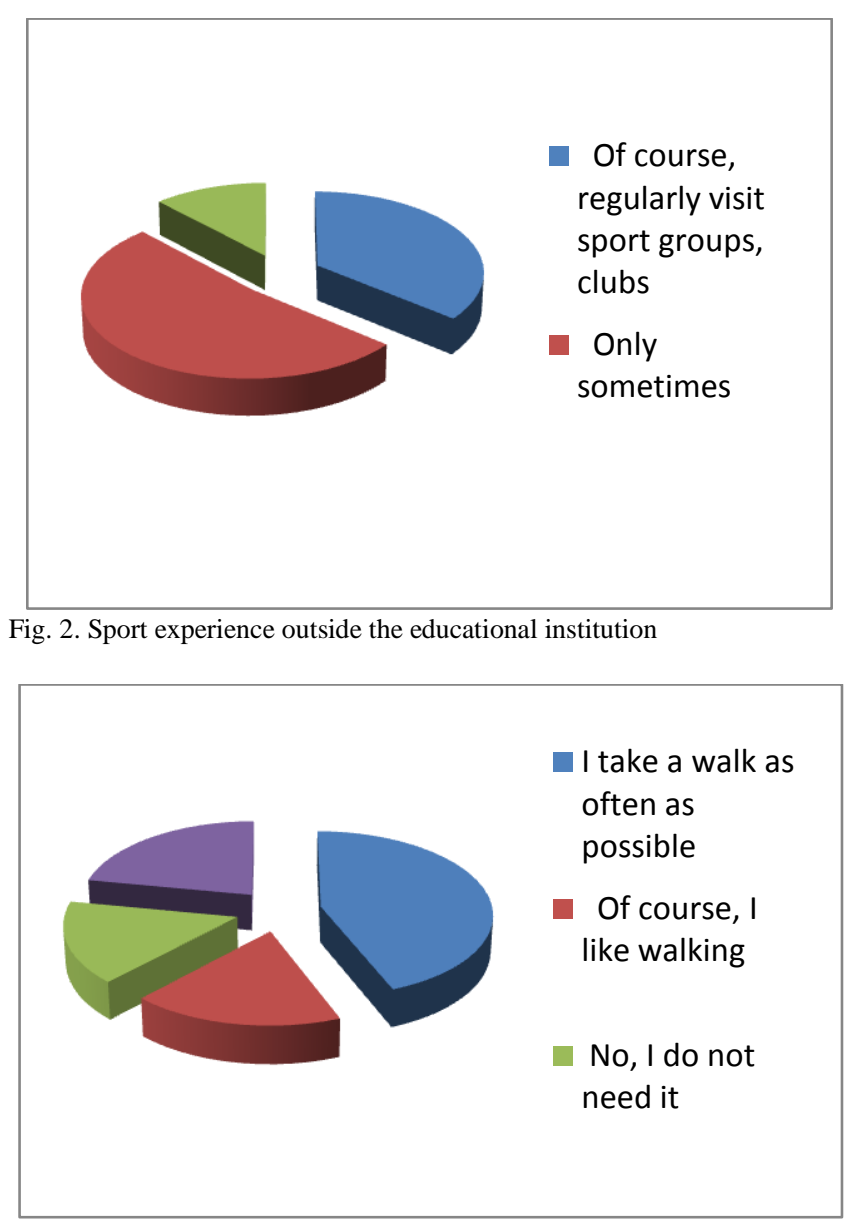

Fig. 3. Attitude to classes of physical training

- I take a walk as often as possible

- Of course, I like walking

- No, I do not need it

- $\quad$ Fill-in-the- blank yourself

When asked about their attitude to physical education, most students chose the "Neutral" option (32.5\%). The "Negative" option was chosen by $25 \%$ of respondents; $22.5 \%$ do not attend classes because of an exemption from PE classes (health problems), and only $20 \%$ chose the option "Positive".

A question was asked: "What do physical education classes bring to you?" The answers were as follows:

Nothing $28.2 \%$

Only fatigue $23.1 \%$

Positive emotions " $20.5 \%$

Energy $17.9 \%$

Health $-10,3 \%$ 
The data show that only $19 \%$ of the recipients were active participants in sports competitions, and $51 \%$ do not take part in any them at all. At the same time, $38 \%$ of students go in for sports on their own.

Physical education, according to $76 \%$ of respondents, contribute to better health; $70 \%$ think that it increases stamina; $60 \%$ - improve the form of a body.

\section{DISCUSSION}

Thus, defining the technologies of social interaction in the process of physical training, we define three interrelated areas:

- the increase in the effectiveness of the pedagogical impact in the field of physical development based on general cultural values and theoretical knowledge (using methods of study, legal and system-oriented analysis, discussion and evaluation of historical events related to the development of physical education and sports, etc.);

- the development of competencies in the field of physical training impact on human health (discussion of health problems, assessment of modern adaptive training methods, identification of needs, etc.);

- the motivation of physical activity due to competitive activity.

The readiness of students to organize and conduct competitions at various levels can be determined by such indicators as the correct selection of means and methods of organizing physical education and sports events; competent planning of competitions in order to increase the interest of participants in physical education and sports and, as a result, to aspire a tendency to a healthy lifestyle; the organization of mass entertainment competitions, easily understandable by both the participants and the attending spectators.

Competent conduct of competitions contributes to the development of many positive factors. Participants of the competition compare their results with the performances of fellow students and are included in the analytical activity, the success of which increases the self-esteem of students. It is an important determinant of professional consciousness.

\section{CONCLUSION}

In the process of organizing pedagogical activities, the acquired theoretical knowledge should be applied in practice. This means the ability to organize sports and recreation activities based on age and individual characteristics of those involved; have the skill of public speaking; own the techniques of communication with the teams of various institutions; know and apply the means and methods of physical education; possess skills in organizing physical education and health activities and outdoor activities using physical exercises.

The competencies of social interaction include the ability to quickly solve organizational and managerial issues in dynamic conditions, non-standard situations; readiness for responsibility for decisions; competent application of legal documents; ability to organize and conduct public sporting events and competitions; mastering the technology of training; application of modern technologies in the educational process; ensuring control and effective communication (periodic surveys, identifying trends).

\section{References}

[1] Press release of the All-Russian Center for the Study of Public Opinion. URL: https://wciom.ru/index.php?id=236\&uid=9301

[2] Sobon A. ICT Tools Support of Erasmus +: Lessons Learned of Polish Military Universities. International Scientific and Educational Conference "Actual Problems of Education" (February 25-26, 2016). Riga, $2016 . \quad$ URL: http://www.tsi.lv/sites/default/files/editor/science/Conferences/MIP201 6/mip_2016_2v_1.pdf.

[3] Vilensky M.Ya., Gorshkov A.G. Physical education and a healthy lifestyle of a student: a training manual. M.: Knorus. 2013, 240.

[4] Matveev L.P. Theory and methodology of physical education. Introduction to the subject: textbook for higher specials. physical education institutions. StPb.: Lan, M.: Omega-L. 2004, 160.

[5] Lubysheva L.I. The concept of specialists in physical education and sports professional training process modernization. Theory and practice of physical education. 2003, 12, pp. 13-17.

[6] Zimyaya I.A. The hierarchical component structure of educational activity // Educational activity as an object of analysis and evaluation / Under the general. M. 2003.

[7] Gladkov A.V., Kutepov M.M., Trutanova A.V. Development of funds for assessment tools in the implementation of the competency-based approach. Azimuth of scientific research: pedagogy and psychology. 2017, vol. 6, 3(20), pp. 138-142.

[8] Zaitseva I.P. Physical training for bachelors: Evaluation criteria: study guide. Yaroslavl: Yaroslavl State University. 2013, 196.

[9] Roblyer M.D., Knezek G.A. New millennium research for educational technology: A call for a national research agenda. Journal of Research on Technology in Education. 2003, vol. 36(1), pp. 60-71.

[10] Balsevich V.K. The scientific substantiation of innovative transformations in the field of physical training and sports // Theory and practice of physical training. 2001, 1, pp. 10-16.

[11] The Federal Law "On Physical Culture and Sport in the Russian Federation" dated 04.12.2007 N URL://www.consultant.ru/document/cons_doc_LAW_73038/

[12] A competency-based approach to education as the basis for highquality training of physical training specialists: under the edition of A. Ya. Nain. Chelyabinsk: Publishing House of the Ural Academy. 2012, 340 .

[13] Tazieva Z.N. Forms of social interaction in the process of physical training. Bulletin of KazGUKI. 2019, 1, 16.

[14] Alexsandr S. Kuznetsov. Russian Professor's meeting. Russian Journal of Physical Education and Sport. 2019, 14(1), pp. 17-22. DOI: 10.14526/2070-4798-2019-14-1-18-24 